\title{
What can routine germination tests in seed banks tell us about the germination ecology of endemic and protected species?
}

\begin{tabular}{|c|c|}
\hline Journal: & Botany \\
\hline Manuscript ID & cjb-2017-0003.R1 \\
\hline Manuscript Type: & Article \\
\hline Date Submitted by the Author: & 18-Mar-2017 \\
\hline Complete List of Authors: & $\begin{array}{l}\text { Clemente, Adelaide; cE3c - Centre for Ecology, Evolution and } \\
\text { Environmental Changes, Faculdade de Ciências } \\
\text { Müller, Jonas V; Royal Botanic Gardens, Kew, Conservation Science } \\
\text { Almeida, Erika; Jardim Botânico, Museu Nacional de História Natural e da } \\
\text { Ciência, Universidade de Lisboa } \\
\text { Costa, Catarina; cE3c - Centre for Ecology, Evolution and Environmental } \\
\text { Changes, Faculdade de Ciências, Universidade de Lisboa; Jardim Botânico, } \\
\text { Museu Nacional de História Natural e da Ciência, Universidade de Lisboa } \\
\text { Dias, Sara; cE3c - Centre for Ecology, Evolution and Environmental } \\
\text { Changes, Faculdade de Ciências, Universidade de Lisboa; Jardim Botânico, } \\
\text { Museu Nacional de História Natural e da Ciência, Universidade de Lisboa } \\
\text { Brehm, Joana; cE3c - Centre for Ecology, Evolution and Environmental } \\
\text { Changes, Faculdade de Ciências, Universidade de Lisboa; Jardim Botânico, } \\
\text { Museu Nacional de História Natural e da Ciência, Universidade de Lisboa } \\
\text { Rebelo, Rui; cE3c - Centre for Ecology, Evolution and Environmental } \\
\text { Changes, Faculdade de Ciências, Universidade de Lisboa } \\
\text { Martins-Loução, Maria Amélia; cE3c - Centre for Ecology, Evolution and } \\
\text { Environmental Changes, Faculdade de Ciências, Universidade de Lisboa; } \\
\text { Jardim Botânico, Museu Nacional de História Natural e da Ciência, } \\
\text { Universidade de Lisboa }\end{array}$ \\
\hline $\begin{array}{l}\text { Please Select from this Special } \\
\text { Issues list if applicable: }\end{array}$ & N/A \\
\hline Keyword: & $\begin{array}{l}\text { Ex situ conservation, dormancy, seed pre-treatments, seed banking, } \\
\text { temperature }\end{array}$ \\
\hline
\end{tabular}




\section{TITLE}

What can routine germination tests in seed banks tell us about the germination ecology of endemic and protected species?

\section{AUTHOR NAMES AND AFFILIATIONS}

Adelaide S. Clemente ${ }^{1,2}$, Jonas V. Müller ${ }^{3}$, Erika Almeida ${ }^{2}$, Catarina A. Costa ${ }^{1,2}$, Sara Lobo Dias $^{1,2}$, Joana Magos Brehm ${ }^{1,2}$, Rui Rebelo ${ }^{1}$, Maria Amélia Martins-Loução,

${ }^{1} \mathrm{cE} 3 \mathrm{c}$ - Centre for Ecology, Evolution and Environmental Changes, Faculdade de Ciências, Universidade de Lisboa, C2, Campo Grande, 1749-016 Lisboa, Portugal

2Jardim Botânico, Museu Nacional de História Natural e da Ciência, Universidade de Lisboa, Rua da Escola Politécnica 58, 1250-102 Lisboa, Portugal

${ }^{3}$ Royal Botanic Gardens, Kew, Conservation Science, Wakehurst Place, Ardingly, RH17 6TN, United Kingdom

\section{EMAIL ADDRESSES}

maclemente@fc.ul.pt (A. S. Clemente)

j.mueller@kew.org (J. V. Müller)

erikaroldao@gmail.com (E. Almeida)

tarina.ca@gmail.com (C. A. Costa)

saralobodias@gmail.com (S. Lobo Dias)

joanabrehm@gmail.com (J. Magos Brehm)

rmrebelo@fc.ul.pt (R. Rebelo)

maloucao@fc.ul.pt (M. A. Martins-Loução)

\section{CORRESPONDING AUTHOR}

Adelaide S. Clemente. CE3c - Centre for Ecology, Evolution and Environmental Changes, Faculdade de Ciências, Universidade de Lisboa, C2, Campo Grande, 1749-016 Lisboa, Portugal. Email: maclemente@fc.ul.pt. Phone: + 351969008734 


\section{Abstract}

Protocols for the conservation of threatened plants are often constrained by the absence of data on germination ecology. However, seed bank managers periodically monitor the viability of stored seed collections using germination tests. Here, we argue that data from those tests can and should be used to provide information on germination requirements of threatened species. Twelve taxa endemic to Portugal were used as a test case to determine the effect of incubation temperature and pre-treatments upon germination, and to identify major factors eliciting germination and releasing dormancy.

We achieved maximum germination percentages $>95 \%$ for 9 taxa. Temperature significantly affected the final germination and mean germination time in most taxa. Maximum and faster germination at cool temperatures $\left(15^{\circ} \mathrm{C}\right.$ or alternate $\left.20 / 10^{\circ} \mathrm{C}\right)$ was the prevailing trend. Cold stratification improved germination in one species, suggesting physiological dormancy. Scarification increased the germination percentage of one species among those expected to exhibit physical dormancy. Seed bank data provided valuable information on germination ecology, which can be used in in situ conservation, and as a baseline for further germination studies. Given the increasing threats to plant diversity, accessibility to seed bank data is paramount.

Key words:

Ex situ conservation; temperature; dormancy; seed pre-treatments; seed banking; threatened species 


\section{Introduction}

Germination is the first fundamental stage in the life cycle of a plant. By preparing for the subsequent stages of establishment, further growth and development, germination is fundamental for plant adaptation (Donohue et al. 2010). The range of conditions eliciting germination of a plant determines the breadth of its niche and geographic range (Donohue et al. 2010; Luna and Moreno 2010). Among the factors which define the germination niche, temperature is of paramount importance, frequently regulating seed germination (Baskin and Baskin 1998; Probert 2000). As one of several environmental cues, temperature (including seasonal temperatures integrated by the seed over time) also plays a major role inducing or releasing seed dormancy.

Investigating germination traits of individual species is crucial for a better understanding of their ecological requirements and also to develop effective conservation and restoration protocols. Since major changes in the germination phenology and subsequent recruitment are expected under climate change scenarios (Mondoni et al. 2012; Hoyle et al. 2013; Fernández-Pascual et al. 2015), the identification of thermal thresholds for seed dormancy breaking and germination are essential to assess whether a plant is able to cope with temperature regimes that are different and, in many cases, warmer than those it is currently exposed to. Despite the large number of publications characterizing germination niches of individual species or groups of species (e.g. Baskin and Baskin (1998) and references therein; Luna and Moreno (2010)), the available information is often limited for most rare and threatened species, and specific to certain floras (Crawford et al. 2007; Godefroid et al. 2010). The Secretariat of the Convention on

Biological Diversity (2009) has even highlighted that ex situ conservation is often constrained by the absence and/or limited accessibility of data, tools and technologies. Where information is available, a causal relationship between the rarity and the germination niche of a plant species is not evident, although often a family trend is found. On the contrary, species-specific requirements for germination are prevalent, which is frequently attributed to the specific habitats in which those species occur (e.g. high mountain habitats, specific microclimates) (Herranz et al. 2002; Giménez-Benavides et al. 2005; Lorite et al. 2007; Luna and Moreno 2010). Therefore, a thorough understanding of the germination ecology is critical to optimise conservation efforts, and to contribute to a better understanding of potential species responses to climate change. 
Knowledge on the germination of rare and threatened species is of paramount importance for conservation practitioners, enabling them to produce plants and to increase the chance of establishment of self-sustaining populations (Merritt and Dixon 2011).

The identification of optimum germination temperatures and dormancy types requires an appropriate experimental set-up and large seed numbers (but see Baskin and Baskin (2003)), which imposes further constraints to the investigation of germination traits in rare and threatened species. However, when those species are targeted for ex situ conservation in seed banks, seed bank managers monitor the viability of stored seed collections by periodically removing samples for germination testing (Gosling 2003). Ex situ conservation in seed banks is complementary to in situ conservation, and is effectively integrated with the protection of plants in their natural habitats and with the recovery plans of species and habitats (Offord et al. 2004; Merritt and Dixon 2011). The increasing awareness of the effects of climate change on plant distributions and the evidence for range shifts in plant populations as a consequence of climate change (e.g. Mondoni et al. 2012) has also increased the value of seed banks to study and assist in the adaptation of species to environmental change (Walck and Dixon 2009).

Seed bank routine germination tests are designed to determine the maximum potential germination and the viability of the seed accession, and their results will only provide a good indication of seed viability if species specific optimum germination conditions and methods to overcome dormancy are known (Gosling 2003; Hay and Probert 2013). Every year, seed banks perform hundreds or thousands of germination tests, therefore effective and practical germination protocols are required. The general principle of the tests is to incubate seeds under a single, standard (preferably optimal) set of environmental conditions, to achieve the quickest, most uniform and complete germination possible for the seed accession (Gosling 2003). When there is no previous information on the germination requirements of a species, germination conditions and pre-treatments applied are usually based on information obtained from literature, and on experience gained in previous tests performed on related species. Given the common limitations in seed number when handling collections of rare plants, often only one germination pre-treatment is used, usually based on a 'best bet' approach (Crawford et al. 2007; Martyn et al. 2009). 
Although routine germination tests in seed banks do not accommodate complex experimental design to analyse germination and the complex relationship between environmental factors, dormancy and germination traits, we argue that those tests can and should be used to provide information on germination requirements of species conserved when no other data are available. We propose that the data generated by those tests are a valuable source of information on the species' germination ecology. Using 12 taxa endemic to Portugal, our specific research aims were (1) to determine the effect of (a) incubation temperature and (b) pre-treatments upon germination and (2) consequently to assess whether those routine germination tests can be employed to identify major factors eliciting germination and releasing seeds from dormancy, and to contribute to the understanding of the germination ecology of those taxa.

\section{Material and methods}

\section{Target taxa and seed collection}

We used data from routine germination tests stored in the germination database of the A.L. Belo Correia seed bank (Botanical Garden, MUHNAC, University of Lisbon, Portugal). By March 2015, this seed bank stored seeds from 61 taxa from mainland Portugal listed in the EC Habitats Directive 92/43/EEC Annexes. The majority of those was accessioned after 2009 (Clemente and Martins-Loução 2013). For this study, we selected 12 taxa (Table 1) tested for germination before seed storage. Taxa were selected according to three criteria: i) at least two germination tests were performed under different conditions, ii) taxa have been prioritized for national ex situ conservation under a partnership between the A.L. Belo Correia seed bank and the national conservation agency (Instituto da Conservação da Natureza e das Florestas, ICNF), and iii) taxa were endemic to Portugal. Although all selected taxa are endemic to Portugal according to the nomenclature adopted by the Habitats Directive, and used in this study, four taxa underwent relatively recent taxonomic revisions in Flora Iberica (Castroviejo et al. 1993-2013). In consequence, they have new accepted names and larger geographic ranges (Alyssum pintodasilvae Dudley, Jasione crispa (Pourret) Samp. subsp. serpentinica Pinto da Silva, Juncus valvatus Link and Hyacinthoides vicentina (Hoffmanns. \& Link) Rothm. subsp. transtagana, see Table 1 for synonyms). Several taxa have restricted distribution ranges and/or 
specific habitat requirements (e.g. Convolvulus fernandesii Pinto da Silva \& Teles, Table 1). All selected taxa grow under Mediterranean climate with mean annual rainfall ranging from 886 to $735 \mathrm{~mm}$, and mean annual temperature between $12.7^{\circ} \mathrm{C}$ and $20.8^{\circ} \mathrm{C}$ (Bragança, Coimbra, Lisboa and Setúbal weather stations; IPMA 2016).

Fully matured seeds had been collected from wild populations from 2008 to 2013 , each population and collection event representing a separate seed accession. The number of populations sampled for each taxon varied with geographic range, accuracy of information available on population localities, and resources available for seed collection. Herbarium vouchers had also been collected and are stored at the LISU Herbarium. Due to the low seed number collected for some taxa, the number of seed accessions per taxon used in germination trials varied between one and 10 (Appendix A1). Seeds were maintained at room conditions $\left(24.7 \pm 1.4^{\circ} \mathrm{C} ; 52.2 \pm 4.4 \mathrm{RH}\right)$ for one to two weeks before starting the germination experiments.

\section{Germination conditions and pre-treatments}

Information on germination and presence of dormancy for those 12 selected taxa was surveyed in order to identify conditions for the initial germination tests. Published information on successful germination conditions was found for one species only (C. fernandesii (ICN 2007)). Therefore, type of dormancy, successful germination conditions and pre-treatments used for taxonomically related taxa sharing similar habitat and life histories were surveyed in existing seed bank databases (A.L. Belo Correia database, ENSCOBASE (2017) and Seed Information Database (Liu et al. 2008)), as well as in published literature on germination of Mediterranean species (Pérez-García et al. 1995; Escudero et al. 1997; Doussi and Thanos 2002; Copete et al. 2009). When information was available, temperature regimes and pre-treatments to overcome dormancy recommended were applied. For example, physical seed dormancy is common in Convolvulaceae and Fabaceae species (González-Melero et al. 1997; Baskin and Baskin 1998), thus, a scarification pre-treatment was used for taxa belonging to those families. The effects of temperature on final germination and mean germination time (MGT) were tested according to seed availability in each seed accession. Since seed numbers differed among taxa and seed accessions within taxa, the number of temperature regimes and pre-treatments tested was not consistent across taxa and seed accessions. A minimum of two and a maximum of four 
incubation temperature regimes were tested $\left(15^{\circ} \mathrm{C}, 20^{\circ} \mathrm{C}\right.$, and $25^{\circ} \mathrm{C}$ constant temperature, and $20 / 10^{\circ} \mathrm{C}$ alternate temperature (day/night)). Additionally, the effect of pre-treatments on final germination and MGT was tested for four taxa which exhibited low germination percentages in previous trials or that were likely to be dormant. Seeds were either untreated or pre-treated with one of the following dormancy breaking treatments, cold stratification (incubation on agar at $5^{\circ} \mathrm{C}$ for 56 days prior to the germination test), and scarification. Scarification was applied using one of the following methods, chipping with a scalpel, abrasion of seeds between two sheets of sandpaper, and immersion in sulphuric acid $\left(90 \% \mathrm{H}_{2} \mathrm{SO}_{4}\right)$ for 30 minutes. A summary of test conditions and pre-treatments applied to each seed accession is presented in the Appendix A1. A 100-seed lot was assigned to each temperature regime or temperature regime $\mathrm{x}$ pretreatment test, and divided into four replicates with 25 seeds each, using $9 \mathrm{~cm}$ diameter Petri dishes with $1 \%$ agar. Petri dishes were placed in germination incubators (Fitoclima S600 and S600PL, Aralab, Lisbon). All germination tests were conducted in light with a 12 hours photoperiod. Germination (defined as radicle emergence of approximately $1 \mathrm{~mm}$ ) was recorded each day during the first week and afterwards every two or three days. The tests finished when no additional germination was observed for 2-4 weeks. We selected data corresponding to the minimum duration of the monitoring period of each taxon (see Appendix A1), thereby ensuring data comparability within taxon. At the end of the germination test, a cut test determined the number of empty seeds as well as the number of firm and healthy seeds that did not germinate (Gosling 2003). Empty seeds were excluded from the analysis.

Data analysis

Percentage of germination was calculated as number of germinated seeds at the end of the test $/$ (initial number of seeds-number of empty seeds) $\times 100$ (Gosling 2003). Mean germination time (MGT) was calculated as $M G T=\Sigma D n / \sum n$, where $\mathrm{n}$ is the number of seeds that germinate on day $\mathrm{D}$ counted from the start of the germination test (Ellis and Roberts 1980). MGT was not calculated when germination percentage was lower than or equal to $5 \%$. 
Species-specific statistic models were performed depending on the number of fixed factors tested and number of levels within fixed factors. For example, models for taxa with only one seed accession and with no pre-treatment were performed including only temperature as a fixed factor. Taxa with more than one seed accession and with no pre-treatment were analysed setting temperature as fixed factor and seed accession as random factor. When a pre-treatment was applied, both temperature and pre-treatment were included in the model as fixed factors (for detailed information about number of accessions tested within taxa and number of levels of each factor see Appendix A1).

We applied generalised linear mixed effects models (GLMMs) using Laplace approximation and binomial errors (with logit link function) to seed germination data for taxa comprising more than one seed accession (R-package Ime4, Bates et al. 2015). The GLMMs contained temperature regime as explanatory variable and proportion of seeds germinated in each Petri dish as the response variable (coded as number of germinated seeds and number of plum seeds sown). To account for population differences in germination behaviour, seed accession was modelled as a random factor. Similarly, general linear mixed effects models (LMMs) were fitted using MGT as response variable and a normal error distribution, and temperature regime and seed accession as fixed and random factor, respectively. When only one seed accession was available for a specific taxon, general linear (GLMs) and linear (LMs) models were fitted to germination and MGT data, respectively, using the R-package nlme (Pinheiro et al. 2016). Temperature or pretreatment, temperature, and the interaction term were used as fixed factors.

The effect of the fixed factors was evaluated by model selection and likelihood ratio. When overdispersion was detected, quasibinomial error distribution was used to fit the models. Significant terms were identified using a stepwise addition to the null model, and $\chi^{2}$ and $\mathrm{F}$ tests were used to evaluate if selected predictors explained a significant fraction of the deviance. Pvalues for the GLMMs were obtained using the parametric bootstrap method (R-package afex; Singmann et al. 2015). Multiple comparisons were performed using Tukey contrasts (R-package multcomp; Hothorn et al. 2008). All data were analysed in $\mathrm{R}$ version 3.2.3 (R Core Team 2015).

\section{Results}


Maximum germination percentage attained per taxa was higher than $95 \%$ for 9 of the 12 taxa (Figure 1). Only four taxa recorded lower maximum germination percentage, A. pintodasilvae (72\%), C. fernandesii (64\%), P. pallens (69\%) and Saxifraga cintrana (92\%). Germination was faster (MGT $\leq 5$ days) in A. pintodasilvae, I. procumbens subsp. microcarpa, O. kuzinskyanae and Silene longicilia, and slower (MGT $\geq 10$ days) in $H$. vicentina subsp. transtagana, $J$. valvatus and P. pallens (Figure 2).

The temperature regimes tested affected the final germination of all taxa except $J$. crispa subsp. serpentinica, P. pallens, S. semidentata and Saxifraga cintrana (Tables 2 and 3). MGT was affected by temperature in all taxa except $A$. pintodasilvae, O. kuzinskyanae and $P$. pallens (Tables 2 and 3). When the effect of temperature was significant, a generally higher and faster germination was attained at $15^{\circ} \mathrm{C}$ and/or at $20 / 10^{\circ} \mathrm{C}$ compared to $20^{\circ} \mathrm{C}$ or $25^{\circ} \mathrm{C}$ (I. procumbens subsp. microcarpa, J. valvatus, Silene longicilia, O. kuzinskyanae) (Figure 1 and 2). Indeed, germination was lowest and MGT highest at $25^{\circ} \mathrm{C}$ in all accessions of $\mathrm{J}$. valvatus and Silene longicilia tested at this temperature. Only two taxa did not exhibit a decrease in seed germination at $20^{\circ} \mathrm{C}$ (J. crispa subsp. serpentinica and S. semidentata).

The pre-treatments tested had a significant effect both on final germination and on MGT but significant interactions between temperature and pre-treatment were found in $\mathrm{H}$. vicentina subsp. transtagana and $O$. hackelii (Table 3). Germination of $H$. vicentina subsp. transtagana was highest at $15^{\circ} \mathrm{C}$, both in control and pre-treated seeds whereas germination at higher temperatures $\left(20^{\circ} \mathrm{C}\right.$ and $\left.20 / 10^{\circ} \mathrm{C}\right)$ increased only after cold stratification (Figure 1). This pretreatment also accelerated germination (decreased MGT) at all temperatures (Figure 2). On the contrary, Saxifraga cintrana seeds pre-treated by cold stratification exhibited a pronounced reduction in germination compared to control seeds, regardless of incubation temperature (Figure 1). Seed scarification increased the germination percentage of C. fernandesii; germination of pre-treated seeds ranged between 51 and $64 \%$ while control seeds attained only $4 \%$ (Figure 1). In contrast, scarification with sand paper enhanced the germination of O. hackelii only at $20 / 10^{\circ} \mathrm{C}$. Seeds of this species pre-treated with sulphuric acid did not germinate and were dead at the end of the test (data not shown).

\section{Discussion}


Routine seed bank germination tests proved useful for providing information on the germination ecology of the studied taxa. The use of such data when no other sources of information exist would underpin plant production for re-introduction programmes, and the design of more comprehensive studies for a thorough understanding of germination ecology of rare and threatened species. Publishing or making the results from routine germination tests available is a prerequisite for the use of data.

Notwithstanding the relatively low seed numbers that were used (compared to studies planned to test specific hypotheses in the scientific literature, (e.g. Thanos et al. 1995; Copete et al. 2009; Carta et al. 2013), seed bank germination tests still evidenced major trends in optimum germination temperature and species-specific germination requirements. Our results indicate that optimal germination of most of the taxa analysed occurs at cool temperatures $\left(15^{\circ} \mathrm{C}\right.$ or alternate $20 / 10^{\circ} \mathrm{C}$ ), as previously described for several Mediterranean species (e.g. Thanos et al. 1995; Escudero et al. 1997; Carta et al. 2013). However, variation in species response to temperature is evident, as for four taxa (J. crispa subsp. serpentinica, P. pallens, S. semidentata and Saxifraga cintrana) the germination percentage did not vary within the range of temperature regimes tested, while for another one $(H$. vicentina subsp. transtagana) optimal germination occurred at lower temperatures. Requirements for dormancy-breaking were identified in three taxa, H. vicentina subsp. transtagana, C. fernandesii and O. hackelii. Maximum germination at cool temperatures was the prevailing trend. Suppression or reduction of germination at high temperatures could prevent germination during Mediterranean summer months, when occasional rainfall may provide a transient period of conditions suitable for germination but uncertain for seedling establishment due to drought. This strategy associates germination with autumn temperatures and the onset of rainfall, when water availability ensures seedling establishment, and is widely described for Mediterranean species (Thanos et al. 1995; Escudero et al. 1997; Carta et al. 2013). Indeed, even the taxa with a north-eastern distribution range (A. pintadasilvae, J. crispa subsp. serpentinica and S. semidentata) that experience the lowest winter temperatures (IPMA 2016) did not have germination requirements similar to temperate or mountain species, which often exhibit optimal germination at high temperature or require a cold stratification period for germination (Giménez-Benavides et al. 2005). Although the timing of germination in nature is unknown for our taxa, and given the fact that the two 
annuals complete the life cycle in spring, it is likely that most of our taxa initiate germination in autumn or early winter, with seedling establishment and growth before the onset of summer. Most of the studied taxa colonize vegetation gaps or other open habitats. If the seed is in the appropriate microsite, germinating readily after the first rains would be advantageous for early seedling establishment and growth.

Fresh seeds of some Mediterranean species exhibit physiological dormancy immediately after collection; they require an after-ripening period to germinate and to widen the temperature range at which germination occurs (Copete et al. 2009; Mira et al. 2010), thereby preventing germination under high summer temperatures and low soil water availability. Germination of $A$. pintodasilvae, I. procumbens subsp. microcarpa, J. valvatus and Silene longicilia decreased when seeds were incubated at 20 or $25^{\circ} \mathrm{C}$, which suggests that a fraction of the seed collection might be dormant at the moment of dispersal, as shown in some of their congeners (Copete et al. 2009; Mira et al. 2010; Carta et al. 2013). Since seeds of the four taxa are dispersed from early to mid-summer, physiological dormancy would prevent germination during summer. This strategy would be particularly advantageous for J. valvatus, a species characteristic of temporary ponds, by preventing germination after occasional summer rainfall and coupling optimal germination temperature with waterlogged conditions (Tuckett et al. 2010; Carta et al. 2013).

Germination of $H$. vicentina subsp. transtagana occurred at lower temperature $\left(15^{\circ} \mathrm{C}\right)$ and at a slower rate compared to most of the studied taxa. Cold stratification increased germination percentage and rate and widened the range of germination temperatures, indicating that seeds are dormant at dispersal, in spring. Based on the effect of cold stratification, the most probable dormancy type is physiological dormancy (sensu Baskin \& Baskin 1998). However, morphological dormancy cannot be excluded since the embryo seems to have grown after stratification (pers. obs.). Indeed, the congeneric $H$. non-scripta and other related species with a similar phenology initiate embryo growth at seed dispersal but the embryo:seed ratio required for radicle emergence is attained only after exposure to low temperature (Vandelook and Van Assche 2008; Copete et al. 2011; Carta et al. 2014). Suppression of radicle emergence in a fraction of the seed lot, in combination with slow germination may maximize the germination in waterlogged soils. 
Two species were expected to exhibit physical dormancy (C. fernandesii and O. hackelii) based on the prevalence of this type of dormancy in the corresponding plant families (González-Melero et al. 1997; Baskin and Baskin 1998). Indeed, scarification had a remarkable effect in breaking seed dormancy in C. fernandesii, irrespective of incubation temperature, corroborating the presence of physical dormancy in this species. Common environmental factors acting as dormancy breaking stimuli, such as fire (e.g. Luna and Moreno 2010), are not prevalent in the coastal cliffs where this species occurs, but exposure to high temperature and low air humidity during summer, which breaks dormancy in seeds of other Convolvulaceae (Jayasuriya et al. 2009), closely simulates the conditions that seeds of $C$. fernandesii are exposed to after dispersal in their natural environment.

Germination of $O$. hackelii was not enhanced by scarification in two out of three temperature regimes tested. These unexpected results indicate that a significant proportion of seeds does not have impermeable seed coats and germinates in the absence of dormancy breaking stimuli, as documented in other Fabaceae species (Pérez-García et al. 1995; González-Melero et al. 1997; Clemente et al. 2016), and in Cistaceae (Thanos et al. 1992).

Whilst temperature regime and pre-treatments maximizing germination were identified for most taxa, the range of temperatures and pre-treatments tested was limited by the available seed numbers. Therefore, expanding the range of temperatures (e.g. from $5^{\circ} \mathrm{C}$ to $30^{\circ} \mathrm{C}$; Thanos et al. 1995), and identifying the type of dormancy and the ecological significance of high and low temperatures during germination and dormancy breaking, are required to fully analyse seed germination.

Population effects on germination characteristics were not assessed in this study since they were considered to be beyond the main objective. Nevertheless, it is worth remarking that taxa with more than three accessions (A. pintadasilvae, J. valvatus, I. procumbens subsp. microcarpa, S. semidentata and S. longicilia) often exhibited high standard deviations in germination percentage and/or MGT, indicating variation in population responses to temperature. Local environmental conditions affect the germination characteristics of species across a wide range of plant communities (e.g. Baskin and Baskin 1998 and references therein; Giménez-Benavides et al. 2005), and this fact highlights the importance of testing samples from individual populations for viability during seed bank monitoring, rather than assuming an 
identical germination behaviour among different samples of the same species. Conclusions based on data from only one population should therefore be drawn only very carefully. We hope the presented study encourages seed bank managers to make their germination data widely accessible, and the scientific community to use such data as baseline information to design comprehensive studies on seed germination. Some constraints inherent to the germination procedures applied in seed banks (such as limited statistical power due to low sampling sizes or the absence of replicates), may preclude the publication of part of the data in peer-reviewed journals. Nevertheless, such data can still be made available e.g. in on-line reports or databases. Databases such as RBGK's Seed Information Database (Liu et al. 2008) or ENSCOBASE (2017) are currently the largest on-line sources of information on germination requirements. ENSCOBASE currently offers data on ex situ conservation of 11,515 wild taxa stored in 34 native seed banks across Europe, including individual 21,181 germination tests (ENSCOBASE 2017). Standardized templates and private URLs make it straightforward for seed bank managers to upload their germination data.

Taxonomic revisions and the use of different names by different seed bank managers for the same species are major constraints to data uniformization for accessibility, and a difficulty for users searching for information on a specific taxon. Many taxa have alternative names or are placed, depending on the taxonomic concept, into a different taxon, as seen for a few of our target taxa (Table 1). To allow cross-reference between different names and taxonomic concepts, seed bank managers should try to maintain a record of all names of an accession and a list of synonyms. Selecting a prevailing authority for all accepted names and synonyms (e.g., Euro+Med PlantBase (2017), The Plant List (2017)) would also produce a taxonomically consistent list of taxa. Users should be aware of this issue and remain cautious when searching seed bank databases for information on a specific taxon.

\section{Conclusion}

Routine seed bank germination tests provided valuable baseline information on the germination ecology of the studied taxa, which is a basis for more comprehensive scientific studies. Our results are also valuable to develop conservation protocols for rare and threatened species. In general, germination percentages were high and pre-treatments to break seed dormancy are 
easy to apply under controlled conditions, which may compensate the scant seed material available for plant production. Therefore, major efforts should be addressed to those taxa which, in addition to low germination percentages, have a critical conservation status. In our set of 12 studied taxa, C. fernandesii, J. valvatus, O. kuzinskyanae, P. pallens and Saxifraga cintrana had already been identified by the national conservation programme as requiring population reinforcements (PSRN2000 2008). All those taxa reached high germination percentage except P. pallens, which requires additional studies to identify the optimum germination temperature. Overall, high germination percentages obtained indicate that the main threats to the in situ conservation of these taxa are likely to be related to the habitat where seedlings establish or to dispersal or seed viability constraints. Studies addressing seed dispersal mechanisms, the timing of seedling emergence and establishment in nature, and the ability to form a persistent seed bank (Copete et al. 2009) would therefore further enhance conservation and management efforts.

Given the increasing threats to plant diversity (RGB Kew 2016), it is urgently necessary to make use of seed bank germination data. We hope our study encourages other seed banks to publish or promote accessibility to their data, and fosters the communication and cooperation between seed bank managers, conservation practitioners and researchers to maximize the chances of germination of rare and threatened species and their in situ conservation.

\section{Acknowledgements}

We acknowledge the collaboration of the Instituto da Conservação da Natureza e das Florestas, and thank Domitila Brocas for laboratory assistance. We also thank three anonymous reviewers for their constructive comments on the manuscript. This work was supported by the Millennium Seed Bank Partnership, Royal Botanic Gardens, Kew; the Fundo EDP para a Biodiversidade 2009 (Fundação EDP); and the Fundação para a Ciência e a Tecnologia (BGCT/33418/2008, A.S. Clemente).

\section{References}


Baskin, C.C., and Baskin, J.M. 1998. Seeds: ecology, biogeography, and evolution of dormancy and germination. Academic Press, San Diego.

Baskin, C.C., and Baskin, J.M. 2003. When Breaking Seed Dormancy is a Problem. Nativ. Plants 4: 17-21.

Bates, D., Maechler, M., Bolker, B., and Walker, S. 2015. Fitting linear mixed-effects models using Ime4. J. Stat. Softw. 67(1): 1-48. doi:10.18637/jss.v067.i01.

Bilz, M., Kell, S.P., Maxted, N., and Lansdown, R.V. 2011. European Red List of Vascular Plants. Publications Office of the European Union, Luxembourg. doi:10.2779/8515.

Carta, A., Bedini, G., Müller, J.V., and Probert, R.J. 2013. Comparative seed dormancy and germination of eight annual species of ephemeral wetland vegetation in a Mediterranean climate. Plant Ecol. 214(2): 339-349. doi:10.1007/s11258-013-0174-1.

Carta, A., Probert, R., Moretti, M., Peruzzi, L., and Bedini, G. 2014. Seed dormancy and germination in three Crocus ser. Verni species (Iridaceae): implications for evolution of dormancy within the genus. Plant Biol. 16(6): 1065-74. doi:10.1111/plb.12168.

Castroviejo, S. et al. 1993-2013. Flora Iberica. Vols. IV, XIV, XVII and XX [online]. Available from http://www.floraiberica.org [accessed 6 July 2016].

Clemente, A.S., and Martins-Loução, M.A. 2013. Banco de sementes do Jardim Botânico MNHNC: o balanço de uma década. O/EL Bot. (Associação Iberomacaronésica Jard.

Botânicos) 7: 17-18.

Clemente, A.S., Moedas, A.R., Oliveira, G., Martins-Loução, M.A., and Correia, O. 2016. Effect of hydroseeding components on the germination of Mediterranean native plant species. J. Arid Environ. 125: 68-72. doi:http://dx.doi.org/10.1016/j.jaridenv.2015.09.017.

Copete, E., Herranz, J.M., Copete, M.A., Baskin, J.M., and Baskin, C.C. 2011. Non-deep complex morphophysiological dormancy in seeds of the Iberian Peninsula endemic geophyte Merendera montana (Colchicaceae). Seed Sci. Res. 21(4): 267-281.

doi:10.1017/S096025851100016X.

Copete, M.A., Herranz, J.M., and Ferrandis, P. 2009. Seed germination ecology of the endemic Iberian winter annuals Iberis pectinata and Ziziphora aragonensis. Seed Sci. Res. 19(3): 155169. doi:10.1017/S0960258509990079. 
Crawford, A.D., Steadman, K.J., Plummer, J.A., Cochrane, A., and Probert, R.J. 2007. Analysis of seed-bank data confirms suitability of international seed-storage standards for the Australian flora. Aust. J. Bot. 55(1): 18-29. doi:10.1071/BT06038.

Donohue, K., Rubio de Casas, R., Burghardt, L., Kovach, K., and Willis, C.G. 2010.

Germination, postgermination adaptation, and species ecological ranges. Annu. Rev. Ecol. Evol. Syst. 41(1): 293-319. doi:10.1146/annurev-ecolsys-102209-144715.

Doussi, M.A., and Thanos, C. 2002. Ecophysiology of seed germination in Mediterranean geophytes. 1. Muscari spp. Seed Sci. Res. 12(3): 193-201. doi:10.1079/SSR2002111. EIONET 2015. European Topic Centre on Biological Diversity. Species reports under Article 17 of the Habitats Directive (2007-2012) at Member State level [online]. Available from http://art17.eionet.europa.eu/article17/reports2012/species/report/?period=3\&group=Vascular+p lants\&country=PT\&region [accessed 30 November 2015].

Ellis, R.H., and Roberts, E.H. 1980. Towards a rational basis for testing seed quality. In Seed Production. Edited by P.D. Hebblethwaite. Butterworths, London, UK. pp. 605-635.

ENSCOBASE 2017. The European Network Seed Conservation database [online]. Available from http://enscobase.maich.gr/ [accessed 9 March 2017].

Escudero, A., Carnes, L.F., and Pérez-García, F. 1997. Seed germination of gypsophytes and gypsovags in semi-arid central Spain. J. Arid Environ. 36(3): 487-497.

doi:10.1006/jare.1996.0215.

Euro+Med PlantBase 2017. Euro+Med PlantBase - the information resource for EuroMediterranean plant diversity [online]. Available from http://ww2.bgbm.org/EuroPlusMed/ [accessed 9 March 2017].

Fernández-Pascual, E., Seal, C.E., and Pritchard, H.W. 2015. Simulating the germination response to diurnally alternating temperatures under climate change scenarios: Comparative studies on Carex diandra seeds. Ann. Bot. 115(2): 201-209. doi:10.1093/aob/mcu234. Giménez-Benavides, L., Escudero, A., and Pérez-García, F. 2005. Seed germination of high mountain Mediterranean species: Altitudinal, interpopulation and interannual variability. Ecol. Res. 20(4): 433-444. doi:10.1007/s11284-005-0059-4. 
Godefroid, S., Van de Vyver, A., and Vanderborght, T. 2010. Germination capacity and viability of threatened species collections in seed banks. Biodivers. Conserv. 19(5): 1365-1383. doi:10.1007/s10531-009-9767-3.

González-Melero, J.A., Pérez-García, F., and Martínez-Laborde, J.B. 1997. Effect of temperature, scarification and gibberellic acid on the seed germination of three shrubby species of Coronilla L. (Leguminosae). Seed Sci. Technol. 25: 167-175.

Gosling, P.G. 2003. Viability testing. In Seed Conservation - Turning Science into Practice. Edited by R.D. Smith, J.B. Dickie, S.H. Linington, H.W. Pritchard, and R.J. Probert. Royal Botanic Gardens, Kew, Kew, UK. pp. 445-481.

Hay, F.R., and Probert, R.J. 2013. Advances in seed conservation of wild plant species: a review of recent research. Conserv. Physiol. 1: 1-11. doi:10.1093/conphys/cot030.

Herranz, J.M., Ferrandis, P., Copete, M.A., and Martínez-Sánchez, J.J. 2002. Influencia de la temperatura de incubación sobre la germinación de 23 endemismos vegetales ibéricos o iberoafricanos. Investig. Agrar. Prod. y Proteccíon Veg. 17: 229-245.

Hothorn, T., Bretz, F., and Westfall, P. 2008. Simultaneous inference in general parametric models. Biometrical J. 50(3): 346-363. doi:10.1002/bimj.200810425.

Hoyle, G.L., Venn, S.E., Steadman, K.J., Good, R.B., McAuliffe, E.J., Williams, E.R., and Nicotra, A.B. 2013. Soil warming increases plant species richness but decreases germination from the alpine soil seed bank. Glob. Chang. Biol. 19(5): 1549-1561. doi:10.1111/gcb.12135. ICN 2007. Plano nacional de conservação da Flora em perigo (1 fase) (LIFE-Natureza III PI8480 Report). Instituto da Conservação da Natureza, Lisboa [online]. Available from http://ec.europa.eu/environment/life/project/Projects/index.cfm?fuseaction=home.showFile\&rep= file\&fil=LIFE02_NAT_P_008480_LAYMAN.pdf [accessed 2 December 2011].

IPMA 2016. Climate normals [online]. Available from https://www.ipma.pt/en/oclima/normais.clima/ [accessed 10 May 2016]. Jayasuriya, K.M.G.G., Baskin, J.M., and Baskin, C.C. 2009. Sensitivity cycling and its ecological role in seeds with physical dormancy. Seed Sci. Res. 19(1): 3-13. doi:10.1017/S096025850818730X. 
Liu, K., Eastwood, R.J., Flynn, S., Turner, R.M., and Stuppy, W.H. 2008. Seed information database (version 7.1) [online]. Available from http://www.kew.org/data/sid [accessed 26 August 2013].

Lorite, J., Ruiz-Girela, M., and Castro, J. 2007. Patterns of seed germination in Mediterranean mountains: Study on 37 endemic or rare species from Sierra Nevada, SE Spain. Candollea 62 : $5-16$.

Luna, B., and Moreno, J.M. 2010. Range-size, local abundance and germination niche-breadth in Mediterranean plants of two life-forms. Plant Ecol. 210(1): 85-95. doi:10.1007/s11258-010$9740-y$.

Martyn, A.J., Seed, L.U., Ooi, M.K.J., and Offord, C. 2009. Seed fill, viability and germination of NSW species in the family Rutaceae. Cunninghamia 11: 203-212.

Merritt, D.J., and Dixon, K.W. 2011. Restoration seed banks - a matter of scale. Science 332(6028): 424-425. doi:10.1126/science.1203083.

Mira, S., González-Benito, M.E., Ibars, A.M., and Estrelles, E. 2010. Dormancy release and seed ageing in the endangered species Silene diclinis. Biodivers. Conserv. 20(2): 345-358. doi:10.1007/s10531-010-9833-x.

Mondoni, A., Rossi, G., Orsenigo, S., and Probert, R.J. 2012. Climate warming could shift the timing of seed germination in alpine plants. Ann. Bot. 110(1): 155-64. doi:10.1093/aob/mcs097. Offord, C.A., McKensy, M.L., and Cuneo, P.V. 2004. Critical review of threatened species collections in the New South Wales Seedbank: Implications for ex situ conservation of biodiversity. Pacific Conserv. Biol. 10: 221-236. doi:http://dx.doi.org/10.1071/PC040221.

Pérez-García, F., Iriondo, J.M., González-Benito, M.E., Carnes, L.F., Tapia, J., Prieto, J., Plaza, R., and Perez, C. 1995. Germination studies in endemic plant species of the Iberian Peninsula. Isr. J. Plant Sci. 43: 239-247.

Pinheiro, J., Bates, D., DebRoy, S., Sarkar, D., and R Core Team 2016. nlme: Linear and Nonlinear Mixed Effects Models. R package version 3.1-124 [online]. Available from URL http://cran.r-project.org/package=nlme.

Probert, R.J. 2000. The role of temperature in the regulation of seed dormancy and germination. In Seeds: The Ecology of Regeneration in Plant Communities. Edited by M. Fenner. CAB International, Wallingford, UK. pp. 261-292. 
PSRN2000 2008. Plano Sectorial da Rede Natura 2000. Resolução do Conselho de Ministros n.o 115-A/2008 de 21 Julho [online]. Available from https://dre.pt/application/dir/pdf1sdip/2008/07/13901/0000200451.pdf [accessed 30 November 2015].

R Core Team 2015. R: A language and environment for statistical computing. R Found. Stat. Comput. Vienna, Austria [online]. Available from https://www.r-project.org/.

RGB Kew 2016. The State of the World's Plants Report - 2016 [online]. Available from https://stateoftheworldsplants.com/report/sotwp_2016.pdf [accessed 3 November 2016]. Secretariat of the Convention on Biological Diversity 2009. The Convention on Biological Diversity Plant Conservation Report: A Review of Progress in Implementing the Global Strategy of Plant Conservation (GSPC) [online]. Available from https://www.cbd.int/doc/publications/plant-conservation-report-en.pdf [accessed 6 July 2016]. Singmann, H., Bolker, B., and Westfall, J. 2015. afex: Analysis of factorial experiments. R package version 0.15-2 [online]. Available from URL https://cran.r-project.org/package=afex Thanos, C.A., Georghiou, K., Kadis, C., and Pantazi, C. 1992. Cistaceae: a plant family with hard seeds. Isr. J. Bot. 41: 251-263.

Thanos, C.A., Kadis, C.C., and Skarou, F. 1995. Ecophysiology of seed germination in endemic Labiates of Crete. Isr. J. Plant Sci. 43: 227-237.

The Plant List 2017. Version 1.1 [online]. Available from http://www.theplantlist.org/ [accessed 9 March 2017].

Tuckett, R.E., Merritt, D.J., Hay, F.R., Hopper, S.D., and Dixon, K.W. 2010. Dormancy, germination and seed bank storage: a study in support of ex situ conservation of macrophytes of southwest Australian temporary pools. Freshw. Biol. 55(5): 1118-1129. doi:10.1111/j.13652427.2010.02386.x. Vandelook, F., and Van Assche, J.A. 2008. Temperature requirements for seed germination and seedling development determine timing of seedling emergence of three monocotyledonous temperate forest spring geophytes. Ann. Bot. 102(2): 865-75. doi:10.1093/aob/mcn165 Walck, J., and Dixon, K. 2009. Time to future-proof plants in storage. Nature 462(7274): 721. doi:10.1038/462721a. 
Table 1. Target taxa tested for germination before storage in the seed bank.

\begin{tabular}{|c|c|c|c|c|c|c|c|}
\hline Taxon & Family & $\begin{array}{l}\text { Habitats } \\
\text { Directive } \\
\text { Annexes }\end{array}$ & $\begin{array}{l}\text { European } \\
\text { Red List } \\
\text { status }\end{array}$ & Life form & $\begin{array}{l}\text { Range } \\
\left(\mathrm{Km}^{2}\right)\end{array}$ & $\begin{array}{l}\text { Dispersal } \\
\text { (month) }\end{array}$ & Habitat \\
\hline Alyssum pintodasilvae Dudley ${ }^{a}$ & Brassicaceae & IV, V & DD & chamaephyte & 2100 & Jul-Aug & $\begin{array}{l}\text { Subnitrophilous dwarf shrub } \\
\text { communities on skeletal soils } \\
\text { derived from alkaline rocks }\end{array}$ \\
\hline $\begin{array}{l}\text { Convolvulus fernandesii Pinto da Silva } \\
\text { \& Teles }\end{array}$ & Convolvulaceae & $\mathrm{II}^{*}, \mathrm{IV}$ & VU & phanerophyte & 100 & Jun & $\begin{array}{l}\text { Limestone walls and crevices in } \\
\text { coastal cliffs }\end{array}$ \\
\hline $\begin{array}{l}\text { Hyacinthoides vicentina (Hoffmanns. \& } \\
\text { Link) Rothm. subsp. transtagana }^{b}\end{array}$ & Asparagaceae & II, IV & LC & geophyte & 3600 & May & $\begin{array}{l}\text { Shrubland clearings and fallow } \\
\text { land in sandy, clayey or rocky } \\
\text { soils with temporary waterlogging }\end{array}$ \\
\hline $\begin{array}{l}\text { Iberis procumbens Lange subsp. } \\
\text { microcarpa Franco \& Pinto da Silva }\end{array}$ & Brassicaceae & II, IV & $\mathrm{DD}$ & chamaephyte & 5000 & Jul-Aug & $\begin{array}{l}\text { Limestone soils in coastal slopes, } \\
\text { or near the coast }\end{array}$ \\
\hline $\begin{array}{l}\text { Jasione crispa (Pourret) Samp. subsp. } \\
\text { serpentinica Pinto da Silva }^{c}\end{array}$ & Campanulaceae & II, IV & DD & chamaephyte & 400 & Jul-Aug & $\begin{array}{l}\text { Crevices in ultra-alkaline rocky } \\
\text { outcrops, in dry areas }\end{array}$ \\
\hline Juncus valvatus Link ${ }^{a}$ & Juncaceae & II, IV & VU & $\begin{array}{l}\text { proto- } \\
\text { hemicryptophyte }\end{array}$ & 6400 & Jul-Aug & Moist meadows and runoff areas \\
\hline Omphalodes kuzinskyanae Willk. & Boraginaceae & II, IV & VU & therophyte & 400 & Jun & $\begin{array}{l}\text { Shrubland clearings on sandy } \\
\text { soils along the coast }\end{array}$ \\
\hline Ononis hackelii Lange & Fabaceae & $\mathrm{II}^{*}, \mathrm{IV}$ & NT & therophyte & 900 & May & $\begin{array}{l}\text { Meadows in sandy soils, } \\
\text { generally in pine and oak forests }\end{array}$ \\
\hline $\begin{array}{l}\text { Pseudarrhenatherum pallens (Link) J. } \\
\text { Holub }\end{array}$ & Poaceae & II, IV & EN & hemicryptophyte & 2200 & May & $\begin{array}{l}\text { Soil pockets over calcareous } \\
\text { rocks at the edges of scrublands }\end{array}$ \\
\hline $\begin{array}{l}\text { Santolina semidentata Hoffmanns. \& } \\
\text { Link }\end{array}$ & Asteraceae & II, IV & LC & chamaephyte & 1800 & Aug & $\begin{array}{l}\text { Shrublands on rocky outcrops } \\
\text { and soils derived from ultra- } \\
\text { alkaline rocks }\end{array}$ \\
\hline Saxifraga cintrana Kuzinsky ex Willk. & Saxifragaceae & IV & $\mathrm{DD}$ & hemicryptophyte & 2100 & Jun & $\begin{array}{l}\text { Crevices in rocky outcrops and } \\
\text { limestone walls }\end{array}$ \\
\hline Silene longicilia (Brot.) Otth. & Caryophyllaceae & II, IV & LC & hemicryptophyte & 9900 & Jun-Aug & $\begin{array}{l}\text { Shrublands or rock crevices on } \\
\text { limestone soils, as well as in } \\
\text { marls }\end{array}$ \\
\hline
\end{tabular}


Nomenclature according to Habitats Directive. Synonyms in Flora lberica (Castroviejo et al., 1993-2013): ${ }^{a}$ Alyssum serpyllifolium Desf., ${ }^{b}$ Hyacinthoides

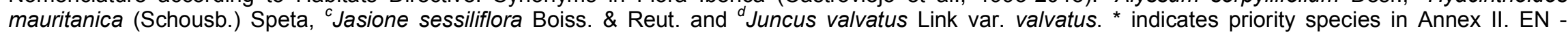
Endangered, VU - Vulnerable, NT - Near Threatened, LC - Least Concern, DD - Data Deficient (threat categories according to IUCN as reported in the European Red List of Vascular Plants (Bilz et al., 2011). Range as reported in EIONET (2015). 
Table 2. Effects of temperature regime and pre-treatment on germination percentage and mean germination time (MGT). Temperature regime was modelled as an explanatory variable (fixed factor). Generalized linear mixed models (GLMM) and Linear mixed models (LMM) were applied to germination percentage and MGT data, respectively, for taxa comprising more than one seed accession. Seed accession was modelled as a random factor. Generalized Linear Models (GLM) and Linear models (LM) were applied to germination percentage and MGT data, respectively, when only one seed accession was available for the taxon. $\chi^{2}$ (germination data with binomial error distribution) and $\mathrm{F}$ (germination data with quasibinomial error distribution, and MGT data) tests and corresponding $p$-values were used to evaluate if selected predictors explained a significant fraction of the deviance.

\begin{tabular}{lllll}
\hline & Germination & & MGT & \\
\cline { 2 - 5 } Species & Model & Significance & Model & Significance \\
\hline A. pintadasilvae & GLMM & $\chi^{2}=13.04, p=0.0030$ & LMM & $F=0.36, p=0.7020$ \\
I. procumbens subsp. microcarpa & GLMM & $\chi^{2}=227.02,0.0010$ & LMM & $F=4.17, p=0.0194$ \\
J. crispa subsp. serpentinica & GLM & $\chi^{2}=8.93, p=0.2277$ & LM & $F=8.12, p=0.0097$ \\
J. valvatus & GLMM & $\chi^{2}=796.03, p=0.0010$ & LMM & $F=184.31, p<0.0001$ \\
O. kuzinskyanae & GLM & $\mathrm{F}=32.80, p<0.0001$ & LM & $\mathrm{F}=1.85, \mathrm{p}=0.2116$ \\
P. pallens & GLM & $\mathrm{F}=0.42, \mathrm{p}=0.5386$ & LM & $\mathrm{F}=6.2849, \mathrm{p}=0.0461$ \\
S. longicilia & GLMM & $\chi^{2}=1181.79,0.0010$ & LMM & $\mathrm{F}=19.51,<0.0001$ \\
S. semidentata & GLMM & $\chi^{2}=0.93,0.6100$ & LMM & $\mathrm{F}=4.34, \mathrm{p}=0.0193$ \\
\hline
\end{tabular}


Table 3. Results of the statistical analysis of the effects of temperature regime and pre-treatment (scarification or cold stratification) on germination percentage and mean germination time (MGT). Generalized Linear Models and Linear models were applied to germination percentage and MGT data, respectively.

Temperature regime, pre-treatment and the interaction term were included as explanatory variables (fixed factors). $\chi^{2}$ (germination data with binomial error distribution) and F (germination data with quasibinomial error distribution, and MGT data) tests and corresponding p-values were used to evaluate if selected predictors explained a significant fraction of the deviance.

\begin{tabular}{llll}
\hline Species & Fixed factor & Germination & MGT \\
\hline C. fernandesii & Temperature & $F=1.87, p=0.1970$ & $F=9.28, p=0.0226$ \\
& Scarification & $F=94.27, p<0.001$ & - \\
H. vicentina subsp. transtagana & Temp $\times$ Scarif & $F=0.17, p=0.6888$ & - \\
& Temperature & $\chi^{2}=44.20, p<0.001$ & $F=52.00, p<0.001$ \\
& Stratification & $\chi^{2}=262.62, p<0.001$ & $F=1054.65, p<0.001$ \\
O. hackelii & Temp $x$ Stratif & $\chi^{2}=26.87, p=0.0002$ & $F=52.67, p<0.001$ \\
& Temperature & $\chi^{2}=63.58, p=0.8318$ & $F=8.01, p=0.0032$ \\
& Scarification & $\chi^{2}=63.95, p=0.1885$ & $F=18.48, p=0.0004$ \\
S. cintrana & Temp $\times$ Scarif & $\chi^{2}=27.88, p<0.001$ & $F=18.47, p<0.001$ \\
& Temperature & $F=3.05, p=0.1060$ & $F=0.005, p=0.94659$ \\
& Stratification & $F=100.36, p<0.001$ & $F=48.95, p<0.001$ \\
* control seeds did not germinate, test applied to the scarification treatment only &
\end{tabular}

$*$ control seeds did not germinate, test applied to the scarification treatment only 


\section{Figure captions}

Figure 1. Germination percentage of the studied taxa under different temperature regimes (A and $B ; 15,20$ and $25^{\circ} \mathrm{C}$ constant and $20 / 10^{\circ} \mathrm{C}$ day/night alternate temperatures) and pre-treatments (B) (mean \pm s.d.). Taxa means in A consider the variability among populations (including population as a random factor in GLMM analysis). For each taxon, mean germination values for each temperature and pre-treatment with different letters are significantly different $(P<0.05$, Tukey tests).

Figure 2. Mean germination time (MGT) of the studied taxa under different temperature regimes (A and B; 15,20 and $25^{\circ} \mathrm{C}$ constant and $20 / 10^{\circ} \mathrm{C}$ day $/$ night alternate temperatures) and pre-treatments (B) (mean \pm s.d.). Lettering as in Figure 1, on the basis of multiple comparison tests, after GLMM analyses. 
A

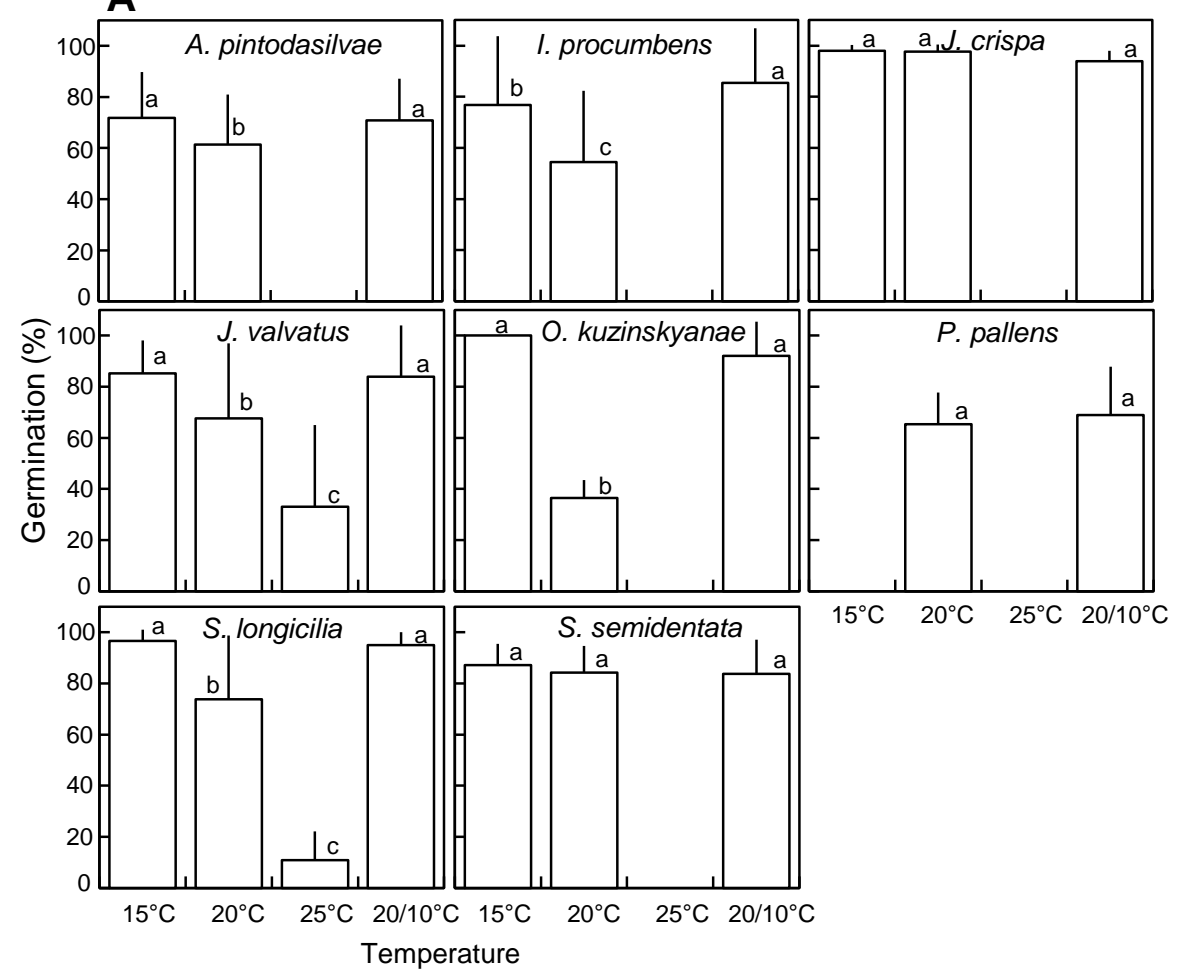

B

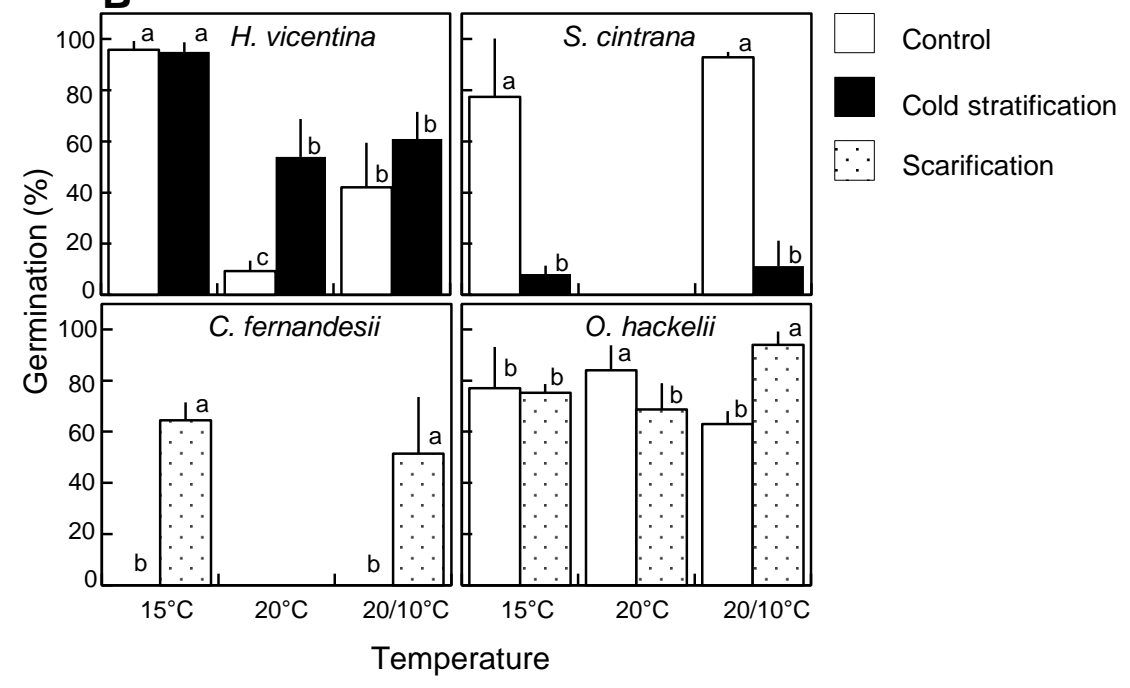




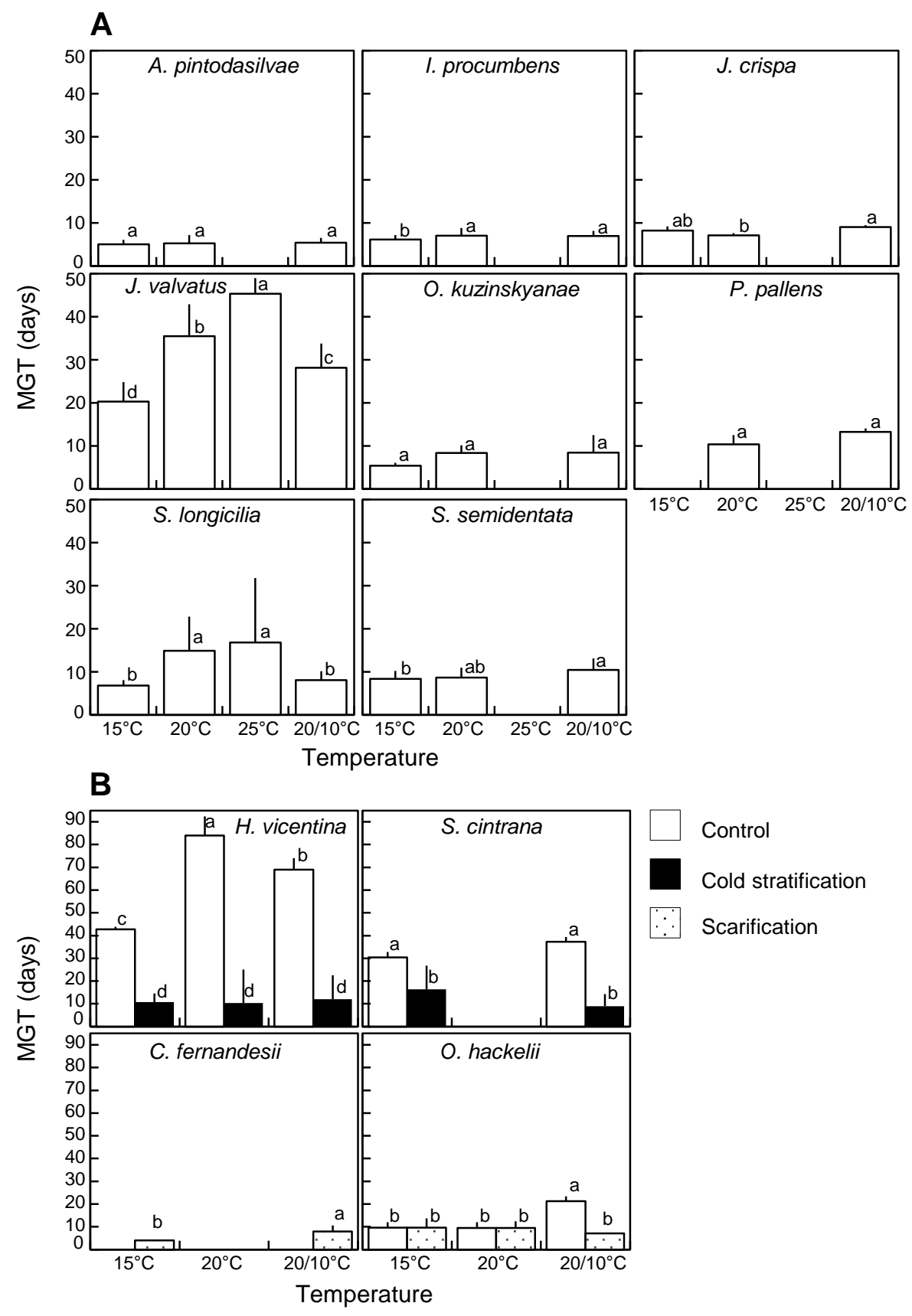




\section{Appendix A1}

Seed accessions tested in each taxon and conditions of the germination tests. The provenance of each accession is indicated by the Portuguese Concelho geographical unit. The experimental design used for each taxon is indicated by the number of accessions tested and the levels tested within each factor (temperature and pre-treatment). Four replicates of 25 seeds were used in each test (temperature level or temperature level $\times$ pre-treatment level).

\begin{tabular}{|c|c|c|c|c|c|c|}
\hline Taxon & Seed accession number ${ }^{\dagger}$ & Collecting date & Provenance & Temperature ${ }^{\ddagger}$ & Pre-treatment & $\begin{array}{l}\text { Test duration } \\
\text { (days) }\end{array}$ \\
\hline A. pintadasilvae & BG.MNHN.UL 009565 & $16-08-2013$ & Bragança & $15^{\circ} \mathrm{C}, 20^{\circ} \mathrm{C}, 20 / 10^{\circ} \mathrm{C}$ & - & 45 \\
\hline A. pintadasilvae & BG.MNHN.UL 009572 & $15-08-2013$ & Vinhais & $15^{\circ} \mathrm{C}, 20^{\circ} \mathrm{C}, 20 / 10^{\circ} \mathrm{C}$ & - & 45 \\
\hline A. pintadasilvae & BG.MNHN.UL 009580 & $14-08-2013$ & Bragança & $15^{\circ} \mathrm{C}, 20^{\circ} \mathrm{C}, 20 / 10^{\circ} \mathrm{C}$ & - & 45 \\
\hline A. pintadasilvae & BG.MNHN.UL 009619 & $11-07-2013$ & Macedo de Cavaleiros & $15^{\circ} \mathrm{C}, 20^{\circ} \mathrm{C}, 20 / 10^{\circ} \mathrm{C}$ & - & 45 \\
\hline C. fernandesii & BG.MNHN.UL 009827 & $10-06-2011$ & Sesimbra & $15^{\circ} \mathrm{C}, 20 / 10^{\circ} \mathrm{C}$ & scarification*, control & 55 \\
\hline $\begin{array}{l}\text { H. vicentina subsp. } \\
\text { transtagana }\end{array}$ & BG.MNHN.UL 009649 & $25-05-2013$ & Palmela & $15^{\circ} \mathrm{C}, 20^{\circ} \mathrm{C}, 20 / 10^{\circ} \mathrm{C}$ & cold stratification $^{\S}$, control & 100 \\
\hline $\begin{array}{l}\text { I. procumbens } \\
\text { subsp. microcarpa }\end{array}$ & BG.MNHN.UL 009711 & 05-08-2012 & Rio Maior & $15^{\circ} \mathrm{C}, 20^{\circ} \mathrm{C}, 20 / 10^{\circ} \mathrm{C}$ & - & 50 \\
\hline $\begin{array}{l}\text { I. procumbens } \\
\text { subsp. microcarpa }\end{array}$ & BG.MNHN.UL 009797 & $17-08-2011$ & Sintra & $15^{\circ} \mathrm{C}, 20^{\circ} \mathrm{C}, 20 / 10^{\circ} \mathrm{C}$ & - & 50 \\
\hline $\begin{array}{l}\text { I. procumbens } \\
\text { subsp. microcarpa }\end{array}$ & BG.MNHN.UL 009798 & $17-08-2011$ & Sintra & $15^{\circ} \mathrm{C}, 20^{\circ} \mathrm{C}, 20 / 10^{\circ} \mathrm{C}$ & - & 50 \\
\hline $\begin{array}{l}\text { I. procumbens } \\
\text { subsp. microcarpa }\end{array}$ & BG.MNHN.UL 009802 & $19-08-2011$ & Vila Franca de Xira & $15^{\circ} \mathrm{C}, 20^{\circ} \mathrm{C}, 20 / 10^{\circ} \mathrm{C}$ & - & 50 \\
\hline $\begin{array}{l}\text { I. procumbens } \\
\text { subsp. microcarpa }\end{array}$ & BG.MNHN.UL 009804 & $19-08-2011$ & Sesimbra & $15^{\circ} \mathrm{C}, 20^{\circ} \mathrm{C}, 20 / 10^{\circ} \mathrm{C}$ & - & 50 \\
\hline $\begin{array}{l}\text { I. procumbens } \\
\text { subsp. microcarpa }\end{array}$ & BG.MNHN.UL 009806 & $11-08-2011$ & Porto de Mós & $15^{\circ} \mathrm{C}, 20 / 10^{\circ} \mathrm{C}$ & - & 50 \\
\hline $\begin{array}{l}\text { I. procumbens } \\
\text { subsp. microcarpa }\end{array}$ & BG.MNHN.UL 009978 & $11-07-2008$ & Setúbal & $15^{\circ} \mathrm{C}, 20^{\circ} \mathrm{C}, 20 / 10^{\circ} \mathrm{C}$ & - & 50 \\
\hline serpentinica & BG.MNHN.UL 009608 & $14-07-2013$ & Vinhais & $15^{\circ} \mathrm{C}, 20^{\circ} \mathrm{C}, 20 / 10^{\circ} \mathrm{C}$ & - & 50 \\
\hline
\end{tabular}




\begin{tabular}{|c|c|c|c|c|c|c|}
\hline J. valvatus & BG.MNHN.UL 009799 & $17-08-2011$ & Sintra & $\begin{array}{c}15^{\circ} \mathrm{C}, 20^{\circ} \mathrm{C}, 25^{\circ} \mathrm{C} \\
20 / 10^{\circ} \mathrm{C}\end{array}$ & - & 55 \\
\hline J. valvatus & BG.MNHN.UL 009801 & $19-08-2011$ & Vila Franca de Xira & $\begin{array}{c}15^{\circ} \mathrm{C}, 20^{\circ} \mathrm{C}, 25^{\circ} \mathrm{C} \\
20 / 10^{\circ} \mathrm{C}\end{array}$ & - & 55 \\
\hline J. valvatus & BG.MNHN.UL 009808 & $10-08-2011$ & Azambuja & $\begin{array}{c}15^{\circ} \mathrm{C}, 20^{\circ} \mathrm{C}, 25^{\circ} \mathrm{C} \\
20 / 10^{\circ} \mathrm{C}\end{array}$ & - & 55 \\
\hline J. valvatus & BG.MNHN.UL 009810 & $10-08-2011$ & Alenquer & $\begin{array}{c}15^{\circ} \mathrm{C}, 20^{\circ} \mathrm{C}, 25^{\circ} \mathrm{C} \\
20 / 10^{\circ} \mathrm{C}\end{array}$ & - & 55 \\
\hline J. valvatus & BG.MNHN.UL 009821 & $05-08-2011$ & Loures & $\begin{array}{c}15^{\circ} \mathrm{C}, 20^{\circ} \mathrm{C}, 25^{\circ} \mathrm{C} \\
20 / 10^{\circ} \mathrm{C}\end{array}$ & - & 55 \\
\hline J. valvatus & BG.MNHN.UL 009823 & 05-08-2011 & Sintra & $\begin{array}{c}15^{\circ} \mathrm{C}, 20^{\circ} \mathrm{C}, 25^{\circ} \mathrm{C} \\
20 / 10^{\circ} \mathrm{C}\end{array}$ & - & 55 \\
\hline J. valvatus & BG.MNHN.UL 009824 & 04-08-2011 & Sintra & $\begin{array}{c}15^{\circ} \mathrm{C}, 20^{\circ} \mathrm{C}, 25^{\circ} \mathrm{C} \\
20 / 10^{\circ} \mathrm{C}\end{array}$ & - & 55 \\
\hline J. valvatus & BG.MNHN.UL 009911 & $19-07-2010$ & Loures & $\begin{array}{c}15^{\circ} \mathrm{C}, 20^{\circ} \mathrm{C}, 25^{\circ} \mathrm{C} \\
20 / 10^{\circ} \mathrm{C}\end{array}$ & - & 55 \\
\hline O. hackelii & BG.MNHN.UL 009847 & $21-05-2011$ & Santiago do Cacém & $15^{\circ} \mathrm{C}, 20^{\circ} \mathrm{C}, 20 / 10^{\circ} \mathrm{C}$ & scarification $^{* *}$, control & 60 \\
\hline O. kuzinskyanae & BG.MNHN.UL 009941 & $15-06-2010$ & Cascais & $15^{\circ} \mathrm{C}, 20^{\circ} \mathrm{C}, 20 / 10^{\circ} \mathrm{C}$ & - & 30 \\
\hline P. pallens & BG.MNHN.UL 009850 & $05-05-2011$ & Alenquer & $20^{\circ} \mathrm{C}, 20 / 10^{\circ} \mathrm{C}$ & - & 40 \\
\hline S. cintrana & BG.MNHN.UL 009764 & $10-06-2012$ & Porto de Mós & $15^{\circ} \mathrm{C}, 20^{\circ} \mathrm{C}, 20 / 10^{\circ} \mathrm{C}$ & cold stratification $^{\S}$, control & 50 \\
\hline S. longicilia & BG.MNHN.UL 009707 & 07-08-2012 & Arruda dos Vinhos & $15^{\circ} \mathrm{C}, 20^{\circ} \mathrm{C}, 20 / 10^{\circ} \mathrm{C}$ & - & 60 \\
\hline S. longicilia & BG.MNHN.UL 009714 & $19-07-2012$ & Condeixa-a-Nova & $15^{\circ} \mathrm{C}, 20 / 10^{\circ} \mathrm{C}$ & - & 60 \\
\hline S. longicilia & BG.MNHN.UL 009723 & $18-07-2012$ & Ansião & $15^{\circ} \mathrm{C}, 20 / 10^{\circ} \mathrm{C}$ & - & 60 \\
\hline S. longicilia & BG.MNHN.UL 009734 & $16-07-2012$ & Porto de Mós & $15^{\circ} \mathrm{C}, 20 / 10^{\circ} \mathrm{C}$ & - & 60 \\
\hline S. longicilia & BG.MNHN.UL 009769 & 02-06-2012 & Loures & $15^{\circ} \mathrm{C}, 20 / 10^{\circ} \mathrm{C}$ & - & 60 \\
\hline S. longicilia & BG.MNHN.UL 009835 & 28-06-2011 & Sintra & $\begin{array}{c}15^{\circ} \mathrm{C}, 20^{\circ} \mathrm{C}, 25^{\circ} \mathrm{C} \\
20 / 10^{\circ} \mathrm{C}\end{array}$ & - & 60 \\
\hline S. Iongicilia & BG.MNHN.UL 009841 & $09-06-2011$ & Mafra & $\begin{array}{c}15^{\circ} \mathrm{C}, 20^{\circ} \mathrm{C}, 25^{\circ} \mathrm{C} \\
20 / 10^{\circ} \mathrm{C}\end{array}$ & - & 60 \\
\hline
\end{tabular}




\begin{tabular}{|c|c|c|c|c|c|c|}
\hline S. Iongicilia & BG.MNHN.UL 009842 & 09-06-2011 & Cadaval & $\begin{array}{c}15^{\circ} \mathrm{C}, 20^{\circ} \mathrm{C}, 25^{\circ} \mathrm{C} \\
20 / 10^{\circ} \mathrm{C}\end{array}$ & - & 60 \\
\hline S. longicilia & BG.MNHN.UL 009843 & $01-06-2011$ & Sintra & $15^{\circ} \mathrm{C}, 20^{\circ} \mathrm{C}$ & - & 60 \\
\hline S. longicilia & BG.MNHN.UL 009902 & $14-07-2010$ & Figueira da Foz & $\begin{array}{c}15^{\circ} \mathrm{C}, 20^{\circ} \mathrm{C}, 25^{\circ} \mathrm{C} \\
20 / 10^{\circ} \mathrm{C}\end{array}$ & - & 60 \\
\hline S. semidentata & BG.MNHN.UL 009567 & $16-08-2013$ & Vinhais & $15^{\circ} \mathrm{C}, 20^{\circ} \mathrm{C}, 20 / 10^{\circ} \mathrm{C}$ & - & 60 \\
\hline S. semidentata & BG.MNHN.UL 009571 & $15-08-2013$ & Vinhais & $15^{\circ} \mathrm{C}, 20^{\circ} \mathrm{C}, 20 / 10^{\circ} \mathrm{C}$ & - & 60 \\
\hline S. semidentata & BG.MNHN.UL 009578 & $14-08-2013$ & Bragança & $15^{\circ} \mathrm{C}, 20^{\circ} \mathrm{C}, 20 / 10^{\circ} \mathrm{C}$ & - & 60 \\
\hline
\end{tabular}

